\title{
Chronic kidney disease alters lipid trafficking and inflammatory responses in macrophages: effects of liver $\mathrm{X}$ receptor agonism
}

Ryohei Kaseda', Yohei Tsuchida', Hai-Chun Yang ${ }^{1,2}$, Patricia G. Yancey ${ }^{3}$, Jianyong Zhong ${ }^{1}$, Huan Tao ${ }^{3}$, Aihua Bian ${ }^{4}$, Agnes B. Fogo 1,2,3, Mac Rae F. Linton ${ }^{3,5}$, Sergio Fazio ${ }^{6}$, Talat Alp Ikizler ${ }^{3}$ and Valentina Kon ${ }^{1 *}$

\begin{abstract}
Background: Our aim was to evaluate lipid trafficking and inflammatory response of macrophages exposed to lipoproteins from subjects with moderate to severe chronic kidney disease (CKD), and to investigate the potential benefits of activating cellular cholesterol transporters via liver $X$ receptor (LXR) agonism.

Methods: LDL and HDL were isolated by sequential density gradient ultracentrifugation of plasma from patients with stage 3-4 CKD and individuals without kidney disease $\left(\mathrm{HDL}^{\mathrm{CKD}}\right.$ and $\mathrm{HDL}^{\text {Cont }}$, respectively). Uptake of $\mathrm{LDL}$, cholesterol efflux to HDL, and cellular inflammatory responses were assessed in human THP-1 cells. HDL effects on inflammatory markers (MCP-1, TNF-a, IL-1 $\beta$ ), Toll-like receptors-2 (TLR-2) and - 4 (TLR-4), ATP-binding cassette class A transporter (ABCA1), NF-KB, extracellular signal regulated protein kinases 1/2 (ERK1/2) were assessed by RT-PCR and western blot before and after in vitro treatment with an LXR agonist.

Results: There was no difference in macrophage uptake of $L D L$ isolated from CKD versus controls. By contrast, HDCKD was significantly less effective than $\mathrm{HDL}^{\text {Cont }}$ in accepting cholesterol from cholesterol-enriched macrophages (median 20. $8 \%$ [IQR 16.1-23.7] vs control (26.5\% [IQR 19.6-28.5]; $p=0.008)$. LXR agonist upregulated ABCA1 expression and increased cholesterol efflux to $\mathrm{HDL}$ of both normal and CKD subjects, although the latter continued to show lower efflux capacity. $\mathrm{HDL}^{\mathrm{CKD}}$ increased macrophage cytokine response (TNF-a, MCP-1, IL-1 $\beta$, and NF-KB) versus $\mathrm{HDL}^{\text {Cont }}$. The heightened cytokine response to $\mathrm{HDL}^{\mathrm{CKD}}$ was further amplified in cells treated with LXR agonist. The LXR-augmentation of inflammation was associated with increased TLR-2 and TLR-4 and ERK1/2.

Conclusions: Moderate to severe impairment in kidney function promotes foam cell formation that reflects impairment in cholesterol acceptor function of HDL ${ }^{C K D}$. Activation of cellular cholesterol transporters by LXR agonism improves but does not normalize efflux to $\mathrm{HDL}^{\mathrm{CKD}}$. However, LXR agonism actually increases the pro-inflammatory effects of $\mathrm{HDL}^{\mathrm{CKD}}$ through activation of TLRs and ERK1/2 pathways.
\end{abstract}

Keywords: HDL, CKD, Macrophages, Cholesterol efflux, LXR

\footnotetext{
* Correspondence: valentina.kon@vanderbilt.edu

'Departments of Pediatrics, Vanderbilt University Medical Center, 1161 21st

Avenue South, C-4204 Medical Center North, Nashville, TN 37232-2584, USA

Full list of author information is available at the end of the article
} 


\section{Background}

Chronic kidney disease (CKD) has reached epidemic proportions, affecting $10-13 \%$ of the global population [1-3]. Cardiovascular disease (CVD) is responsible for most of the deaths in the CKD population. While CVD mortality is due to different causes, atherosclerotic CAD is consistently higher in CKD than in the general population $[4,5]$ and potentiation of CVD risk is seen even for modest impairment in kidney function, which constitutes the largest fraction of the CKD population [6-10]. The mechanisms by which CKD imparts the heightened CVD risk remain unclear, constraining development of risk-reduction interventions in this population. Lipid-lowering agents, primarily statins, are the therapeutic cornerstone to decrease CVD risk. However, even in the general population this intervention provides incomplete risk reduction, a shortcoming that becomes more evident among subjects with CKD.

The hallmark of atherosclerotic plaque is macrophage accumulation of cholesterol and transformation into foam cells, consequence of the unrelenting uptake of atherogenic lipoproteins, and of the failure to mobilize excess cholesterol to extracellular cholesterol acceptors, primarily HDL [11-13]. Epidemiologic studies have established that reduced HDL cholesterol (HDL-C) is associated with increased CVD; however, increasing HDL levels by drug therapies have not resulted in clinical benefits [14-16]. These observations have given rise to the concept of dysfunctional HDL to include impaired efflux capacity and pro-inflammatory properties. Importantly, recent human studies indicate that reduced HDL cholesterol efflux is an independent CVD risk factor [17-20], as capacity of HDL to stimulate cholesterol efflux from cultured macrophages predicted subclinical atherosclerosis and coronary artery disease in non-CKD populations. Consequently, conditions that impair cholesterol efflux or promote cellular uptake can accelerate atherosclerosis and CVD even in the absence of hypercholesterolemia, and may also foster resistance to treatment with lipid-lowering agents.

We, and others, have shown that patients with end stage renal disease (ESRD) requiring dialysis have dysfunctional HDL with reduced efflux and increased inflammation [21-30]. Less is known about the extent to which earlier stages of CKD affect HDL functionality. Although moderate CKD decreases HDL's anti-inflammatory response, the impact on efflux capacity is less understood [22, 27, 29, $31-34]$. It is also unclear whether, and which of the HDL functionalities can be modified. Increasing kidney function by renal transplantation can improve HDL antiinflammatory/anti-oxidant function but not cholesterol handling [29]. There are no studies evaluating the utility of targeting macrophage cholesterol handling and inflammation that might constitute additional therapeutic targets beyond kidney transplantation or standard lipid lowering. Interestingly, we previously showed that uninephrectomy- induced amplification of murine atherosclerosis is linked to impaired cholesterol efflux reflecting repression of macrophage ATP-binding cassette transporter A1 (ABCA1) [35]. Liver $\mathrm{X}$ receptors $(\mathrm{LXR})$ directly activate $\mathrm{ABCA} 1$, and experimental and clinical studies support potentially beneficial effects of LXR agonism to decrease foam cell formation and atherosclerosis in non-CKD settings [36, 37]. Therefore, we sought to evaluate both lipid handling and inflammatory response to lipoproteins of patients with moderate to severe (stage 3 and 4) CKD and assess the potential benefits of activating cellular cholesterol transporters with LXR agonism.

\section{Methods}

\section{Study population}

The study was approved by the Institutional Review Board at Vanderbilt University Medical Center (VUMC). Written informed consent was obtained from all participants. All subjects with CKD $(n=72)$ were followed at the Nephrology Clinic of VUMC. CKD stages 3-4 (GFR 30-59 mL/ $\mathrm{min} / 1.73 \mathrm{~m}^{2}$ and $15-29 \mathrm{~mL} / \mathrm{min} / 1.73 \mathrm{~m}^{2}$, respectively) were determined by CKD-EPI equation [38]. Healthy controls had estimated GFR $>60 \mathrm{~mL} / \mathrm{min} / 1.73 \mathrm{~m}^{2}$ and no proteinuria $(n=31)$. Patients with history of active connective tissue disease, acute infection within one month prior to the study, advanced liver disease, gastrointestinal dysfunction requiring parenteral nutrition, active malignancy, immunosuppressive drugs within one month prior to the study, history of myocardial infarction or cerebrovascular event within 3 months prior to the study were excluded. Some samples were insufficient and the number analyzed is shown in the Table and Results sections.

\section{Isolation of LDL and HDL fractions from blood}

Blood samples were by collected by venipuncture into EDTA tubes, centrifuged at $1700 \mathrm{~g}$ for $15 \mathrm{~min}$ at $4 \mathrm{oC}$ and promptly processed. Five-hundred $\mu \mathrm{l}$ aliquots were stored at $-80 \mathrm{oC}$ for biochemical determinations and NMR lipoprotein analysis, while the rest of the plasma was further processed for isolation of HDL or LDL (CKD, $n=63$ and Controls, $n=25)$. The HDL fractions $(\mathrm{d}=1.063$ to $1.21 \mathrm{~g} /$ $\mathrm{ml})$ and LDL fractions $(\mathrm{d}=1.019$ to $1.063 \mathrm{~g} / \mathrm{ml})$ were isolated from fresh plasma of each subject by density gradient ultracentrifugation after adjustment with potassium bromide [39]. HDL was frozen at $-80{ }^{\circ} \mathrm{C}$ and thawed only once which we and others have shown as having minimal effect on functionality $[18,21,40]$. LDL was used immediately after isolation.

Plasma levels of total cholesterol, triglycerides and HDL were measured enzymatically (Cliniqa, CA). Highsensitivity C-reactive protein (hsCRP) was measured using a high sensitivity immunoturbidimetric assay as previously described (Roche Modular System, Indianapolis, IN) [41]. HDL particle concentration and particle size of lipoprotein 
was evaluated from $500 \mu \mathrm{l}$ plasma by LIPOSCIENCE (Raleigh, NC) using their proprietary NMR methodology.

\section{Macrophage uptake of LDL and cholesterol efflux from lipid-loaded macrophages to HDL}

THP-1 cells were plated and differentiated into macrophages by RPMI 1670 containing 10\% fetal bovine serum and $50 \mathrm{ng} /$ $\mathrm{ml}$ phorbol 12-myristate 13-acetate [21]. The cells then incubated with low density lipoprotein (LDL) $(100 \mu \mathrm{g} / \mathrm{ml})$ for $24 \mathrm{~h}$. Cholesterol content was measured by gas chromatography $[39,42]$ and cholesterol uptake determined as the percent at baseline versus after incubation with LDL [43]. Cell protein content was measured by bicinchoninic acid assay. Efflux assessment followed many of the steps described for uptake including cellular differentiation, which was followed by cholesterol enrichment with acetylated LDL $(100 \mu \mathrm{g} / \mathrm{ml}$, Intracel, Frederick, MA) and exposure to HDL $(50 \mu \mathrm{g} / \mathrm{ml})$ and LPS (50 ng/ml) for $24 \mathrm{~h}$. Cellular cholesterol content was measured by gas chromatography and efflux determined as the percent cellular cholesterol at baseline versus post HDL exposure as described [39, 42].

\section{Macrophage inflammatory cytokine response}

Macrophage expression of cytokines, inflammatory markers, transporters and signaling molecules were assessed by RT-PCR and western blotting. HDL modulation of the inflammatory effect was measured using the established cytokine response in LPS-activated macrophages [21]. THP-1 cells were plated and differentiated into macrophages. Total RNA was extracted from cells with Trizol reagent (Life Technologies, Carlsbad, CA). Quantification of human interleukin (IL)-1 $\beta$, monocyte chemoattractant protein-1 (MCP-1), tumor necrosis factor $\alpha(\mathrm{TNF} \alpha)$, and endogenous control human Euk 18S rRNA levels was performed by real-time reverse transcriptase polymerase chain reaction (PCR) using CFX96 ${ }^{\text {ma }}$ RealTime System (BIO-RAD, Hercules, CA). Probes for IL-1 $\beta$ (Hs99999029_m1), MCP-1 (Hs00234140_m1), TNF $\alpha$ (Hs99999043_m1), ABCA1(Hs01059122_m1), Toll like receptor (TLR)2(Hs01872448_s1), TLR4(Hs00152939_m1) and 18S rRNA were obtained from Applied Biosystems (Foster City, CA). For western blot assessment, macrophages exposed to HDL and LPS for $4 \mathrm{~h}$ were lysed with RIPA buffer from Boston Bio Products (Ashland, MA). Equal amounts of protein were separated on $4-12 \% \mathrm{Nu}$ PAGE Bis-tris gel and transferred onto nitrocellulose membranes immunostained with primary antibodies against phosphorylated p44/42 MAPK from Cell Signaling Technology (Danvers, MA) and subsequently with HRPconjugated second antibody. Blots were visualized using Western Lightning Plus-ECL from Perkin Elmer (Waltham, MA) and developed on film. After incubation with Restore Western Blot Stripping Buffer from Thermo (Rockford, IL), the membranes were immunostained with primary antibody for total p44/42 MAPK from Cell Signaling Technology. To quantify protein expression, western blots were analyzed by ImageJ. NF- $\mathrm{kB}$ activity was determined as previously described [44]. Briefly, $10 \mu \mathrm{g}$ nuclear extract from each of the groups was incubated with $1 \mu \mathrm{L}$ of $50 \mathrm{nM}$ NF-kB oligonucleotide (LI-COR Biotechnology). for $20 \mathrm{~min}$, gel assay performed in 5\% TBE native acrylamide gel. The signals were captured on Odyssey scan system (Li-COR Biotechnology). In studies to activate $\mathrm{ABC}$ transporter, liver $\mathrm{X}$ receptor (LXR) agonist T0901317 (1 $\mu$ M, SIGMA) was added.

\section{Statistics}

Results are expressed as a mean of triplicate assays. Descriptive statistics are presented as frequencies and percentages for categorical variables and median (interquartile range $[\mathrm{IQR}]$ ) for continuous variables. Demographic and clinical factors were compared between control and patients with CKD using Wilcoxon test for continuous variables and Pearson Chi-square test for categorical variables. Spearman correlation was used to assess the correlation between age and efflux in controls and CKD patients. Separate proportional odds models were used to examine the association between efflux or cytokines and group with adjustment for age. Statistical analyses were performed using $\mathrm{R}$ version 2.10.0. A 2-sided significance level of $5 \%$ was deemed statistically significant.

\section{Results}

\section{Characteristics of study subjects}

Demographic, clinical and biochemical characteristics of all participants are summarized in Table 1. The CKD group was older although sex and race were not different. There were no statistically significant differences between CKD and controls in levels of plasma total cholesterol, LDL, HDL or the size of the HDL particles. As expected, CKD patients had significantly elevated plasma triglycerides and higher hsCRP levels than controls.

\section{Macrophage uptake of LDL}

Since foam cell formation reflects an imbalance between lipoprotein uptake and cholesterol efflux, we evaluated the macrophage cholesterol-loading capacity with the LDL fractions isolated from individuals with normal kidney function $(73.1 \%[67.5,75.6], n=5)$ and those with CKD (64.9\% [59.4, 70.4], $\mathrm{n}=5, p=0.63)$. LDL isolated from CKD caused a similar degree of cholesterol accumulation in THP-1 macrophages as did LDL isolated from controls.

\section{Efflux capacity of HDL}

In contrast to cellular uptake of LDL isolated from CKD $(n=58)$ and controls $(n=20)$, cholesterol acceptor function from cholesterol loaded THP-1 cells was significantly 
Table 1 Characteristics of Study Subjects

\begin{tabular}{|c|c|c|c|}
\hline & Control $(n=31)$ & CKD $(n=72)$ & $P$ Value \\
\hline Age (year) & $49.9 \pm 10.6$ & $61.9 \pm 13.5$ & $P<0.05$ \\
\hline Gender (male/female) & $11 / 20$ & $40 / 32$ & NS \\
\hline Race (AA/Caucasian/Other) & $1 / 29 / 1$ & $15 / 56 / 1$ & NS \\
\hline eGFR $\left(\mathrm{ml} / \mathrm{min} / 1.73 \mathrm{~m}^{2}\right)$ & $\geqq 60$ & $33.7 \pm 11.3$ & $P<0.05$ \\
\hline hsCRP (mg/dl) & $3.83 \pm 5.47$ & $8.22 \pm 9.90$ & $P<0.05$ \\
\hline Total cholesterol (mg/dl) & $158 \pm 37$ & $162 \pm 44$ & NS \\
\hline $\mathrm{TG}(\mathrm{mg} / \mathrm{dl})$ & $98 \pm 43$ & $161 \pm 97$ & $P<0.05$ \\
\hline LDL (mg/dl) & $92 \pm 33$ & $88 \pm 31$ & NS \\
\hline HDL size $(\mathrm{nm})$ & $9.12 \pm 0.46$ & $9.07 \pm 0.51$ & NS \\
\hline $\mathrm{HDL}-\mathrm{C}(\mathrm{mg} / \mathrm{dl})$ & $44.5 \pm 8.4$ & $40.9 \pm 12.3$ & NS \\
\hline HDL particles $(\mu \mathrm{mol} / \mathrm{L})$ & $30.1 \pm 5.7$ & $28.5 \pm 6.2$ & NS \\
\hline - Large HDL particles ( $\mu \mathrm{mol} / \mathrm{L})$ & $5.3 \pm 2.7$ & $4.8 \pm 3.1$ & NS \\
\hline - Medium HDL particles ( $\mu \mathrm{mol} / \mathrm{L})$ & $9.4 \pm 5.7$ & $7.5 \pm 5.3$ & NS \\
\hline - Small HDL particles ( $\mu \mathrm{mol} / \mathrm{L})$ & $15.4 \pm 6.2$ & $16.1 \pm 6.2$ & NS \\
\hline apoAl1 (mg/dl) & $125 \pm 16$ & $123 \pm 24$ & NS \\
\hline
\end{tabular}

$A A$ African American, triglyceride, $H D L$ high density lipoprotein, $L D L$ low density lipoprotein, $h s C R P$ high-sensitivity $C$ reactive protein. hsCRP and all lipid and lipoprotein assays were done in Controls $(n=18)$ and CKD $(n=53)$

lower for $\mathrm{HDL}^{\mathrm{CKD}}$ versus $\mathrm{HDL}^{\mathrm{Cont}}$ (median 20.8\%, IQR 16.1-23.7, vs 26.5\%, IQR 19.6-28.5, $n=49,20$, respectively, $p=0.01$ ) (Fig. 1a). Efflux was not significantly correlated with age in the CKD group (spearman rho $=0.02, p=0.90$ ) or in controls (spearman rho $=0.37, p=0.11$ ) [21]. After adjustment for age, there was no significant difference between the CKD and control groups $(p=0.42)$.

To assess whether activation of cellular transporters affect the acceptor capacity of HDL, we exposed THP-1 cells to an LXR agonist (T0901317), which significantly increased gene and protein expression of ABCA1 in cells exposed to $\mathrm{HDL}^{\mathrm{CKD}}$ and $\mathrm{HDL}^{\mathrm{Cont}}$ (Fig. 1b, c). Upregulation in cellular ABCA1 significantly increased cholesterol efflux to $\mathrm{HDL}^{\text {Cont }}$. Although LXR agonism also increased cholesterol efflux with exposure to $\mathrm{HDL}^{\mathrm{CKD}}$, efflux to $\mathrm{HDL}^{\mathrm{CKD}}$ remained significantly lower than HDL ${ }^{\text {Cont }}(P<0.005)$ (Fig. 1d). The difference in efflux in LXR-exposed cells persisted between CKD and control groups after adjustment for age $(p=0.01)$.

\section{Anti-inflammatory capacity of HDL}

We also investigated the cellular inflammatory response elicited by HDL from the same subjects in whom we assessed cholesterol handling. HDL ${ }^{\mathrm{CKD}}$ caused a greater cytokine response in THP-1 cells compared with that observed in cells treated with $\mathrm{HDL}^{\mathrm{Cont}}$ (Fig. 2). After adjustment for age, there were statistically significant differences between CKD and controls for the proinflammatory cytokines (IL1 $\beta, p<0.001$; TNF $\alpha, p=$ 0.04 ; MCP-1, $p=0.06$ ). Further, while exposure of LXR agonist-treated cells to $\mathrm{HDL}^{\text {Cont }}$ did not significantly affect the TNF $\alpha$ or MCP-1 cytokine response (TNF $\alpha$, $1.09[0.79,1.32]$ vs $1.24[1.21,1.61]$ with LXR, $p=0.94$, and MCP-1, $0.96[0.81,1.17]$ vs $1.21[0.77,1.33]$ with LXR, $p=0.94$ ), exposing LXR-treated cells to $\mathrm{HDL}^{\mathrm{CKD}}$ potentiated the inflammatory response, further increasing cellular expression of IL-1 $1(p<0.01)$ and MCP-1 $(p$ $=0.055)$ (Fig. 3).

We next examined the possible pathways involved in the enhanced inflammatory response of LXR-treated cells to $\mathrm{HDL}^{\mathrm{CKD}}$. The amplification was not related to a differential effect on NF- $\kappa B$. Whereas cells exposed to HDL ${ }^{\mathrm{CKD}}$ had greater abundance of NF- $\mathrm{kB}$ than cells exposed to $\mathrm{HDL}^{\text {Cont }}$, there was little difference between LXR-treated and untreated cells (Fig. 4). By contrast, while LXR agonist had little effect on TLR2 expression in cells exposed to $\mathrm{HDL}^{\text {Cont }}$, there was a significant increase in TLR2 expression in the cells exposed to HDL ${ }^{\mathrm{CKD}}$ (Fig. 5). Treatment with LXR agonist also increased TLR4 expression in cells exposed to either HDL ${ }^{\text {Cont }}$ or HDL ${ }^{\mathrm{CKD}}$, a result compatible with TLR4 being a ligand for LPS, which we used in our experimental procedure (Fig. 5). Since ERK1/2, play critical roles in production of proinflammatory cytokines, we also examined this pathway in the $\mathrm{HDL}^{\mathrm{CKD}}$-induced cytokine potentiation in LXR treated cells. There was no difference in ERK1/2 activation between cells exposed to $\mathrm{HDL}^{\text {Cont }}$ or HDL ${ }^{\mathrm{CKD}}$. However, in cells treated with LXR agonist, only HDL ${ }^{\mathrm{CKD}}$ but not $\mathrm{HDL}^{\text {Cont }}$ increased ERK1/2 activation (Fig. 6).

\section{Discussion}

Our data indicate that HDL isolated from patients with moderate to severe CKD has impaired capacity to elicit 

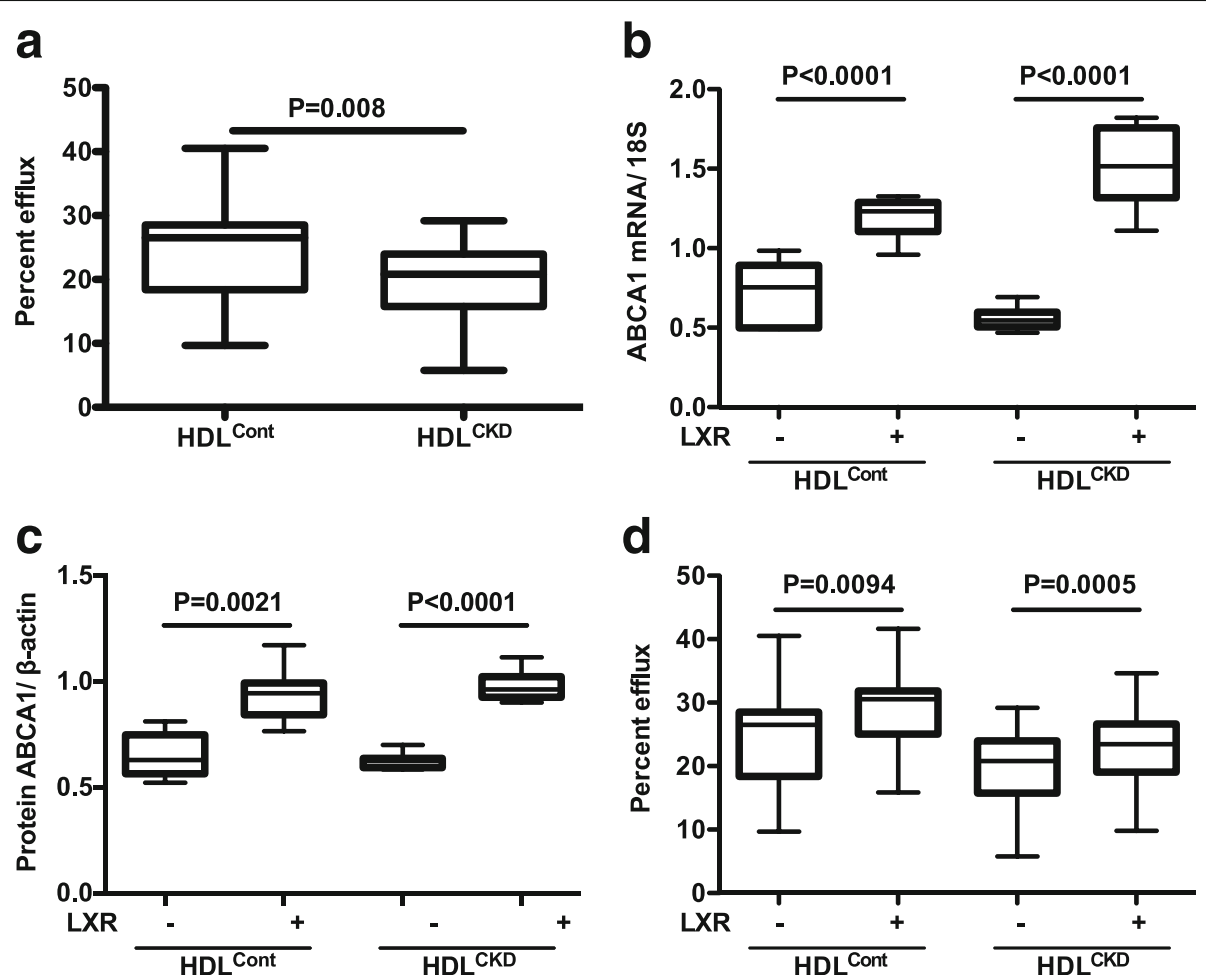

d

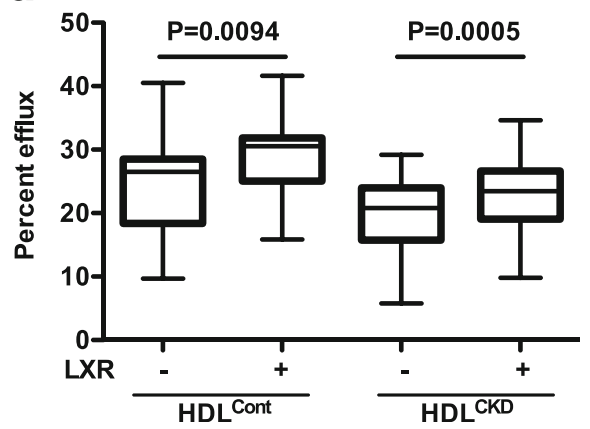

Fig. 1 Efflux from lipid loaded THP-1 macrophages to HDL isolated from patients with chronic kidney disease (CKD) and controls with normal kidney function (Control) (a). ABCA1 mRNA and protein in THP-1 macrophages with/without LXR agonist (b and c). Cholesterol efflux from THP-1 macrophages with/without activation of ABCA1 transporters by LXR agonist (d)

cholesterol efflux from lipid-loaded macrophages and potentiates inflammation, compared with HDL of individuals with normal kidney function. Both cholesterol handling and regulation of vascular inflammation represent potentially atheroprotective functions of HDL that may be influenced by pharmacologic intervention. We show that upregulation of ABCA1 transporters with LXR agonism significantly increases cellular cholesterol efflux both to normal HDL and to the dysfunctional HDL from CKD patients. However, and unexpectedly, LXR activation also amplifies the already heightened cellular inflammatory cytokine response to HDL ${ }^{\text {CKD }}$ by mechanisms linked to activation of TLRs and the ERK1/2 pathway.
These results have important implications. First, our data show that even moderate CKD modifies HDL function and promotes cellular cholesterol accumulation. Interestingly, the lipid accumulation does not reflect greater uptake of LDL. Although macrophage uptake of unmodified LDL is small, CKD is well recognized to cause LDL oxidation which would augment cellular cholesterol loading via scavenger receptor uptake [45]. However, we did not see increased uptake and instead observed significantly impaired cholesterol efflux, results that echo previous findings by us and others in patients with ESRD on dialysis [21, 23, 24, 27, 29]. The results also complement findings by Shroff et al. who reported a

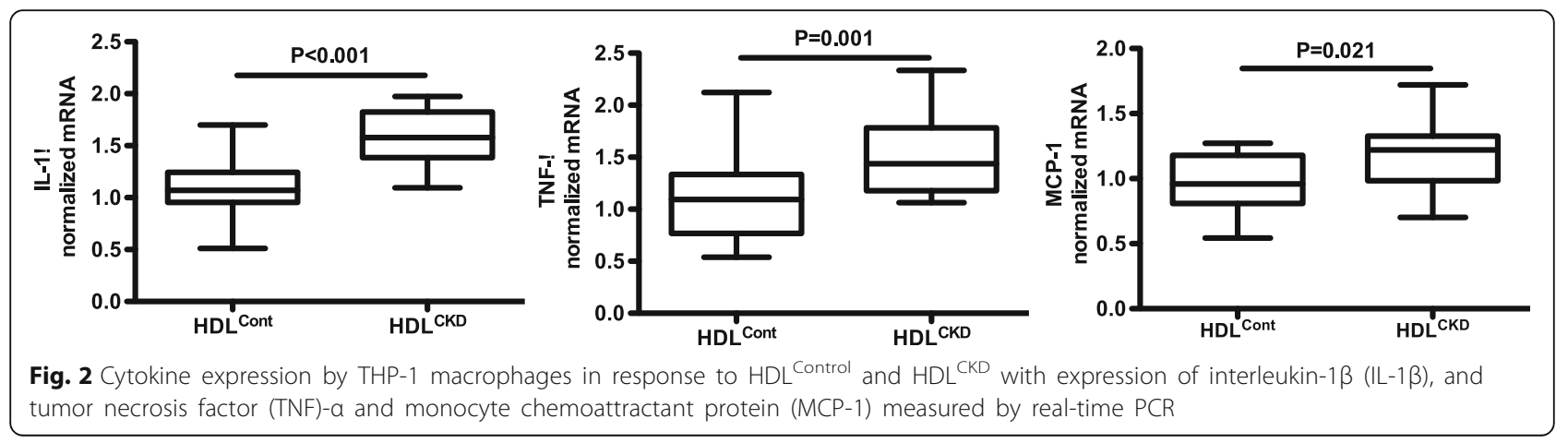



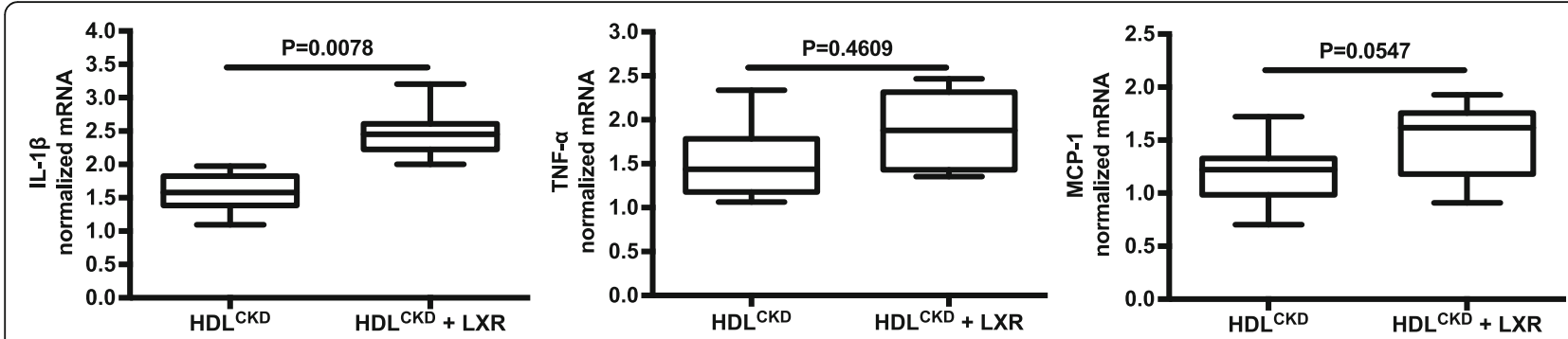

Fig. 3 Cytokine expression of LXR-treated THP-1 macrophages to HDL ${ }^{C K D}$ with expression of interleukin-1 $\beta$ (IL-1 $\beta \beta$, and tumor necrosis factor (TNF)- $a$ and monocyte chemoattractant protein (MCP-1) measured by real-time PCR

graded change in cholesterol efflux capacity in children with CKD stage 2-5 [29]. By contrast, a recent study reported no difference in cholesterol efflux capacity of HDL from normal subjects and individuals with various degrees of kidney impairment (pre-dialysis, maintenance hemodialysis and transplant recipients). However, the HDL concentration used in the assay was only $20 \%$ of that commonly applied in efflux assays and may have been insufficient to effectively elicit cholesterol movement from lipid-laden cells [46]. Taken together, our findings support the hypothesis that even moderate kidney impairment causes HDL dysfunction, including reduced capacity for cholesterol efflux. These observations have particular importance since moderate to severe degree of CKD comprise $>50 \%$ of all patients with kidney disease and because efflux capacity has been shown to be a marker for atherosclerosis and risk of cardiovascular events in individuals without kidney damage, although not patients requiring dialysis [17, 18, 47]. Implications of these findings are further heightened by the fact that standard lipid-lowering therapies reduce the CVD risk by only $20 \%$. Thus, there is the potential of sizable additional residual CV risk reduction in the high risk CKD population using therapies targeted at this derangement [48].

Our data suggest that age might have some impact on HDL's efflux capacity, observations that complement the previously described effects of aging on HDL function [49]. Specifically, adjustment for age eliminated the statistically significant difference in efflux capacity between the CKD and control groups. Interestingly, there were no differences in efflux capacity between CKD and controls in individuals who were less than 50 years old. It is interesting that cellular activation of LXR also increased cholesterol efflux to both $\mathrm{HDL}^{\mathrm{Cont}}$ and $\mathrm{HDL}^{\mathrm{CKD}}$, the statistically significant difference persisting after adjustment for age. These data suggest the possibility that, even in the face of dysfunctional HDL, improving cellular transporter activity can increase cholesterol export, which would predict a reduction in foam cells in the arterial wall. Our finding indicate that this may be beneficial to CKD patients regardless of age. Such therapeutic

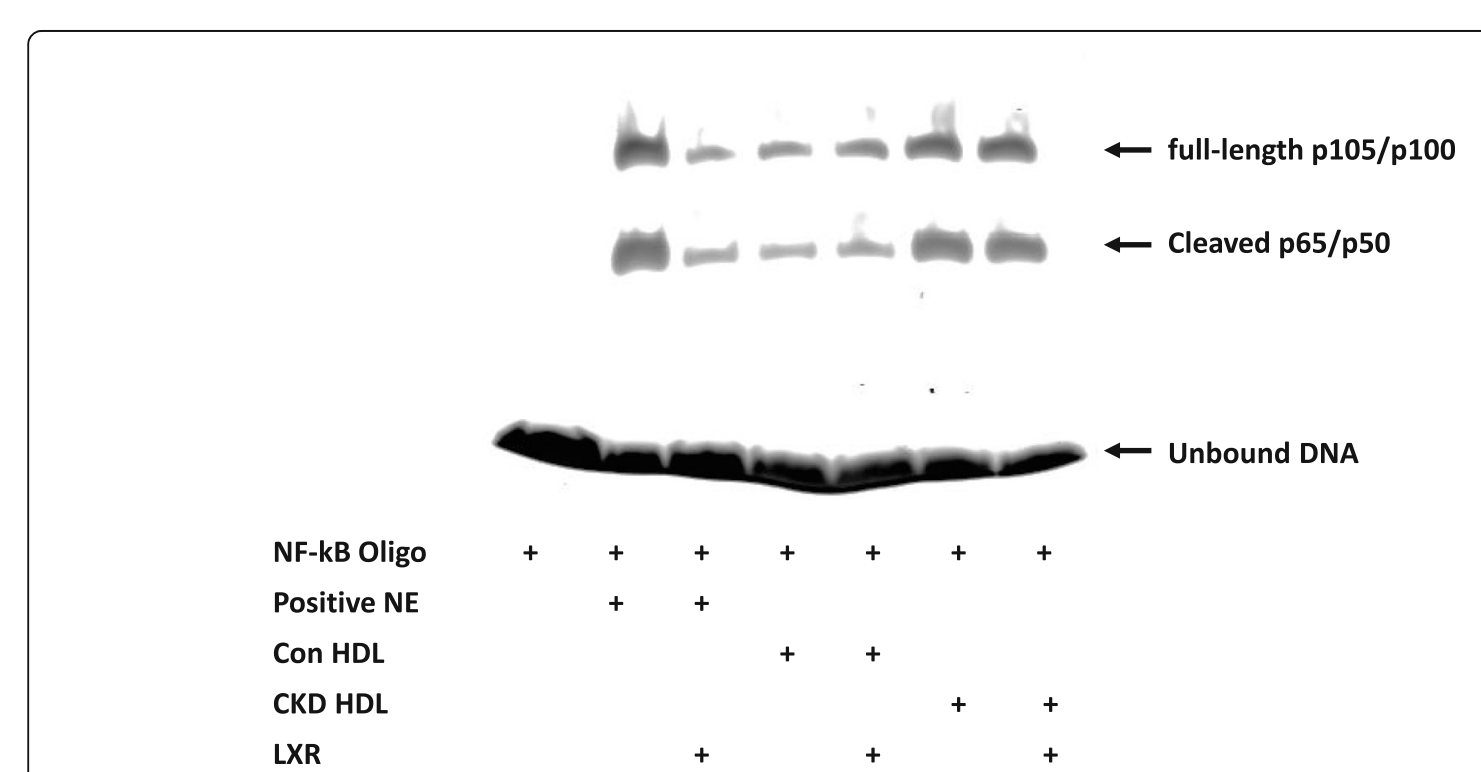

Fig. 4 Electrophoretic mobility-shift assay (EMSA) of NF-KB activity in macrophages with/without LXR agonist exposed to HDL isolated from patients with chronic kidney disease (CKD) and controls with normal kidney function (Control) 


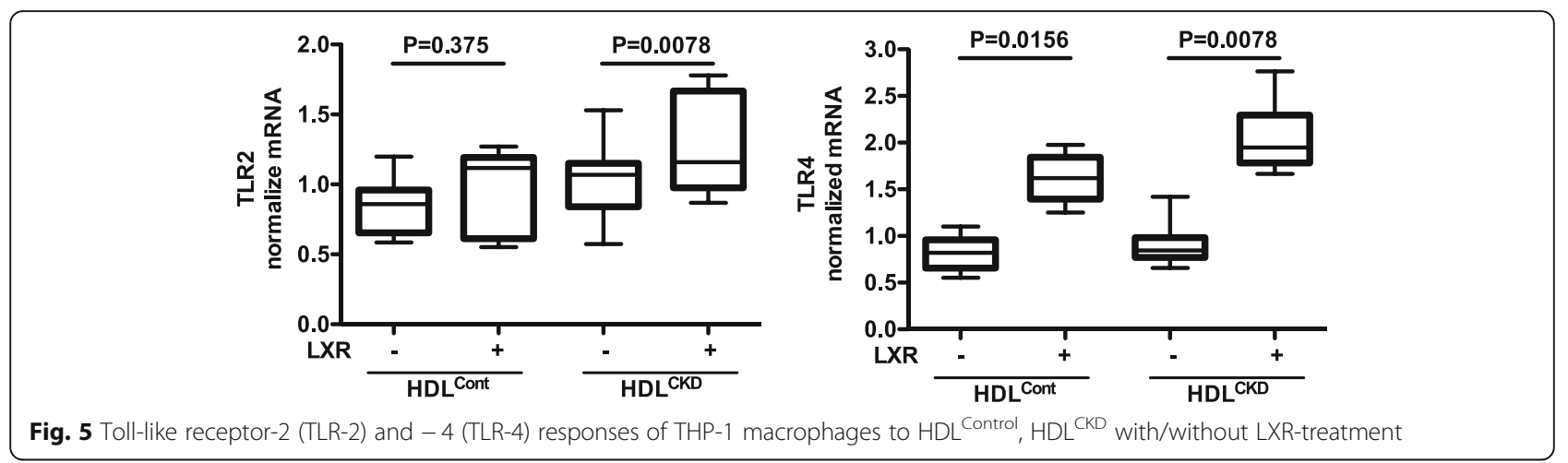

possibility is supported by experimental observations that synthetic LXR agonists can decrease atherosclerosis in animal models through mechanisms that include macrophage efflux and increased reverse cholesterol transport [37, 50].

In addition to modulating cholesterol transport, LXR activators have been shown to have anti-inflammatory effects that may be critically important in their antiatherogenic effects [36]. Therefore, we also assessed the effects of LXR agonism on the cellular inflammatory response using the same HDL samples applied to the efflux assay. Our results show macrophage expression of IL-1 $\beta$, IL- 6 , and TNF- $\alpha$ is greater in response to $\mathrm{HDL}^{\mathrm{CKD}}$ than $\mathrm{HDL}^{\text {Cont }}$. Furthermore, LXR-activated cells exposed to $\mathrm{HDL}^{\mathrm{CKD}}$ showed unexpected potentiation in the inflammatory response (Fig. 3). These results suggest that while HDL ${ }^{\mathrm{CKD}}$ is abnormal in terms of both efflux and inflammation, the abnormalities are not synchronized and therapeutic modalities may have variable effects on distinct HDL actions.
Interestingly, a recent study reported that treatment of $\mathrm{LDLR}^{-/-}$mice with the LXR activator T0901317, substantially reduced the extent of atherosclerotic lesions, independent of the macrophage $\mathrm{ABCA} 1 / \mathrm{G} 1$ cholesterol efflux pathways [36]. Instead, the beneficial effects of LXR activation reflected the anti-inflammatory actions of LXR thought to be mediated through transrepression mechanisms involving the small ubiquitin-like modifier (SUMO)-ylation of LXR, that targets promoters of NF$\kappa \mathrm{B}$ target genes and results in repression of inflammatory genes downstream of NF- $\mathrm{kB}$ [51]. Our study shows that compared to macrophages exposed to normal HDL, cells exposed to $\mathrm{HDL}^{\mathrm{CKD}}$ have dramatically increased activity of NF-kB (Fig. 4), central role of NF-kB in regulation of inflammatory processes when renal function is reduced [52]. Notably, however, activation of LXR did not affect expression of NF- $\mathrm{kB}$, suggesting that increased cytokine response in this context does not involve the

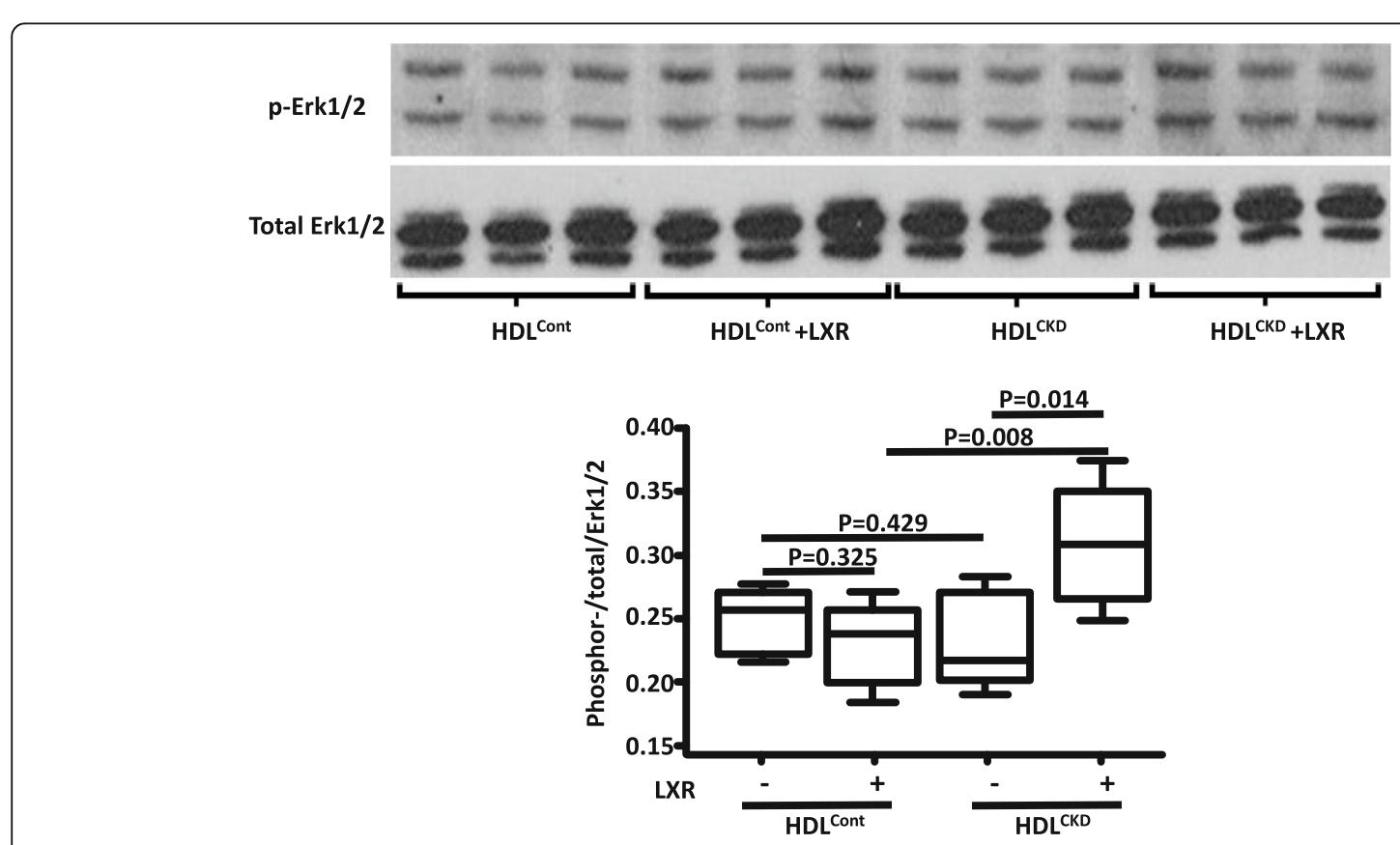

Fig. 6 ERK1/2 in THP-1 macrophages exposed to HDL ${ }^{\text {Control }}, \mathrm{HDL}^{\mathrm{CKD}}$ with/without LXR-treatment 
NF-kB-dependent transrepression pathway. Instead, LXR agonism was associated with direct effects on TLR2 and TLR4. While TLR2 and TLR4 can activate the same signaling pathway, such as JNK, the ERK1/2 pathway is primarily activated by TLR2 [53]. Our data show that both $\mathrm{HDL}^{\mathrm{Cont}}$ and HDL ${ }^{\mathrm{CKD}}$ activate TLR4, whereas only $\mathrm{HDL}^{\text {CKD }}$ activates both TLR4 and TLR2. Moreover, TLR2 activation was associated with phosphorylation of ERK1/2 in response to $\mathrm{HDL}^{\mathrm{CKD}}$. Thus, whereas both TLR4 and TLR2 can stimulate a cytokine response to $\mathrm{HDL}^{\mathrm{Cont}}$ and $\mathrm{HDL}^{\mathrm{CKD}}$, the exaggerated response to $\mathrm{HDL}^{\mathrm{CKD}}$ is more closely linked to TLR2 than TLR4. Our findings that TLRs are involved in $\mathrm{HDL}^{\mathrm{CKD}}$-augmented inflammatory response complements previous reports that TLR2 has a critical role in impaired endothelial protection and anti-inflammatory capacity of HDL isolated from adults and children with stage 2-4 CKD [33]. It is interesting that in human macrophages pretreatment with LXR agonists for $24 \mathrm{~h}$ significantly reduced the inflammatory response induced by LPS whereas longer exposures paradoxically enhanced the inflammatory response [50]. Further, the increased cytokine production involved TLR4 $[54,55]$, as well as cytokine production through pathways driven by TLR2 [55]. The LXR augmentation of TLR-induced cytokine secretion has been proposed as the molecular pathway responsible for synovial inflammation in rheumatoid arthritis [55]. Similarly, it is possible that in the CKD setting, LXR agonism produces undesirable effects by activating TLRs and further potentiating cytokine production.

\section{Conclusions}

Patients with moderate to severe CKD have dysfunctional HDL, which causes impaired cholesterol acceptor function and enhanced inflammatory response in cultured macrophages. Improved cholesterol efflux to $\mathrm{HDL}^{\mathrm{CKD}}$ was achieved by activation of the cellular ABCA1 transporter via LXR. However, our results also show that the potential benefits of LXR-agonism to improve HDL ${ }^{\text {CKD }}$ cholesterol acceptor capacity are possibly offset by its potentiation of the cellular inflammatory cytokine response, which was mediated by activation of TLR2 and 4 and ERK1/2 signaling pathway.

\footnotetext{
Abbreviations

ABCA1: ATP-binding cassette class A transporter; CKD: Chronic kidney disease; CVD: CARDIOVASCULAR disease; ERK1/2: Extracellular signal regulated protein kinases 1/2; ESRD: End stage renal disease; GFR: Glomerular filtration rate; HDL: High-density lipoprotein; HDL-C: HDL cholesterol; hsCRP: High-sensitivity C-reactive protein; IL-1 $\beta$ : Interleukin-1 $\beta$; IQR: Interquartile range; JNK: c-Jun N-terminal kinases; LDL: Low-density lipoprotein; LPS: Lipopolysaccharides.; LXR: Liver X receptor; MAPK: Mitogenactivated protein kinases; MCP-1: Monocyte chemoattractant protein-1; NFKB: Nuclear factor kappa-light-chain-enhancer of activated B cells; RTPCR: Real-time reverse transcriptase polymerase chain reaction; TLR-2: Tolllike receptors-2; TLR-4: Toll-like receptors-4; TNF-a: Tumor necrosis factor a
}

\section{Acknowledgements}

None.

\section{Funding}

This work was supported in part by grants from Merck \#50290 (Kenilworth, NJ), NIH PO1 HL116263 and NIH R01 HL057986. Neither funding agency had a role in the design, collection, analysis, interpretation or writing the manuscript.

\section{Availability of data and materials}

No data has been submitted to any open access databases. All data supporting the study is presented in the manuscript or is available upon request.

\section{Authors' contributions}

RK, YT, HCY. PGY, JZ, and HT are the first authors who were involved in the study design, sample collection, acquired, analysis and interpretation of the data and in the writing of the report. AB performed statics analysis. HCY, $A B F, M F L, S F, T A l$, and $V K$ revised the article critically for important intellectual content. VK is the corresponding author. All authors read and approved the final manuscript.

\section{Competing interest}

Merck \#50290: Mechanisms of CKD-induced Foam Cell Formation. The authors declare that they have no competing interests.

Ethics approval and consent to participate

The study was carried out in accordance with the ethical standards of the Helsinki Declaration and approved by the Institutional Review Board at Vanderbilt University Medical Center (\#121293). Written informed consent was obtained from each patient before any study-specific investigation was performed.

\section{Consent for publication}

The manuscript did not report any individual person's data.

\section{Publisher's Note}

Springer Nature remains neutral with regard to jurisdictional claims in published maps and institutional affiliations.

\section{Author details}

${ }^{1}$ Departments of Pediatrics, Vanderbilt University Medical Center, 1161 21st Avenue South, C-4204 Medical Center North, Nashville, TN 37232-2584, USA. ${ }^{2}$ Pathology, Microbiology and Immunology, Vanderbilt University Medical Center, Nashville, TN, USA. ${ }^{3}$ Medicine, Vanderbilt University Medical Center, Nashville, TN, USA. ${ }^{4}$ Biostatistics, Vanderbilt University Medical Center, Nashville, TN, USA. ${ }^{5}$ Pharmacology, Vanderbilt University Medical Center, Nashville, TN, USA. ${ }^{6}$ Center for Preventive Cardiology, Knight Cardiovascular Institute, Oregon Health \& Science University, Oregon, Portland, USA.

Received: 4 November 2016 Accepted: 15 January 2018

Published online: 27 January 2018

\section{References}

1. Coresh J, Selvin E, Stevens LA, Manzi J, Kusek JW, Eggers P, Van Lente F, Levey AS. Prevalence of chronic kidney disease in the United States. JAMA. 2007;298(17): 2038-47.

2. Rashidi A, Sehgal AR, Rahman M, O'Connor AS. The case for chronic kidney disease, diabetes mellitus, and myocardial infarction being equivalent risk factors for cardiovascular mortality in patients older than 65 years. Am J Cardiol. 2008;102(12):1668-73.

3. Gilbertson DT, Liu J, Xue JL, Louis TA, Solid CA, Ebben JP, Collins AJ. Projecting the number of patients with end-stage renal disease in the United States to the year 2015. J Am Soc Nephrol. 2005;16(12):3736-41.

4. Baber U, Stone GW, Weisz G, Moreno P, Dangas G, Maehara A, Mintz GS, Cristea E, Fahy M, Xu K, et al. Coronary plaque composition, morphology, and outcomes in patients with and without chronic kidney disease presenting with acute coronary syndromes. JACC Cardiovasc Imaging. 2012; 5(3 Suppl):S53-61.

5. Wu Y, Hou J, Li J, Luo Y, Wu S. Correlation between carotid Intima-media thickness and early-stage chronic kidney disease: results from asymptomatic 
Polyvascular abnormalities in community study. Journal of stroke and cerebrovascular diseases : the official journal of National Stroke Association. 2016;25(2):259-65.

6. CDC.GOV: National Chronic Kidney Disease Fact Sheet, 2014. Edited by CDC.GOV.

7. Briasoulis A, Bakris GL. Chronic kidney disease as a coronary artery disease risk equivalent. Curr Cardiol Rep. 2013;15(3):340.

8. Go AS, Chertow GM, Fan D, CE MC, Hsu CY. Chronic kidney disease and the risks of death, cardiovascular events, and hospitalization. N Engl J Med. 2004;351(13):1296-305

9. Stenvinkel P. Chronic kidney disease: a public health priority and harbinge of premature cardiovascular disease. J Intern Med. 2010;268(5):456-67.

10. Tonelli M, Wanner C, Kidney Disease: Improving Global Outcomes Lipid Guideline Development Work Group M. Lipid management in chronic kidney disease: synopsis of the kidney disease: improving global outcomes 2013 clinical practice guideline. Ann Intern Med. 2014;160(3):182.

11. Kon V, Linton MF, Fazio S. Atherosclerosis in chronic kidney disease: the role of macrophages. Nat Rev Nephrol. 2010;7(1):45-54.

12. Rader DJ. Molecular regulation of HDL metabolism and function: implications for novel therapies. J Clin Invest. 2006;116(12):3090-100.

13. Kellner-Weibel G, de la Llera-Moya M. Update on HDL receptors and cellular cholesterol transport. Curr Atheroscler Rep. 2011;13(3):233-41.

14. Investigators A-H, Boden WE, Probstfield JL, Anderson T, Chaitman BR, Desvignes-Nickens P, Koprowicz K, McBride R, Teo K, Weintraub W. Niacin in patients with low HDL cholesterol levels receiving intensive statin therapy. N Engl J Med. 2011;365(24):2255-67.

15. Schwartz GG, Olsson AG, Abt M, Ballantyne CM, Barter PJ, Brumm J, Chaitman BR, Holme IM, Kallend D, Leiter LA, et al. Effects of dalcetrapib in patients with a recent acute coronary syndrome. N Engl J Med. 2012; 367(22):2089-99.

16. Barter PJ, Caulfield M, Eriksson M, Grundy SM, Kastelein JJ, Komajda M, Lopez-Sendon J, Mosca L, Tardif JC, Waters DD, et al. Effects of torcetrapib in patients at high risk for coronary events. N Engl J Med. 2007:357(21):2109-22.

17. Khera AV, Cuchel M, de la Llera-Moya M, Rodrigues A, Burke MF, Jafri K, French BC, Phillips JA, Mucksavage ML, Wilensky RL, et al. Cholesterol efflux capacity, high-density lipoprotein function, and atherosclerosis. N Engl J Med. 2011:364(2):127-35

18. Rohatgi A, Khera A, Berry JD, Givens EG, Ayers CR, Wedin KE, Neeland IJ, Yuhanna IS, Rader DR, de Lemos JA, et al. HDL cholesterol efflux capacity and incident cardiovascular events. N Engl J Med. 2014;371(25):2383-93.

19. Saleheen D, Scott R, Javad S, Zhao W, Rodrigues A, Picataggi A, Lukmanova D, Mucksavage ML, Luben R, Billheimer J, et al. Association of HDL cholesterol efflux capacity with incident coronary heart disease events: a prospective casecontrol study. Lancet Diabetes Endocrinol. 2015;3(7):507-13.

20. Rohatgi A. High-density lipoprotein function measurement in human studies: focus on cholesterol efflux capacity. Prog Cardiovasc Dis. 2015;58(1):32-40.

21. Yamamoto S, Yancey PG, Ikizler TA, Jerome WG, Kaseda R, Cox B, Bian A, Shintani A, Fogo AB, Linton MF, et al. Dysfunctional high-density lipoprotein in patients on chronic hemodialysis. J Am Coll Cardiol. 2012;60(23):2372-9.

22. Kaseda $\mathrm{R}$, Jabs $\mathrm{K}$, Hunley TE, Jones D, Bian A, Allen RM, Vickers KC, Yancey $P G$, Linton MF, Fazio $S$, et al. Dysfunctional high-density lipoproteins in children with chronic kidney disease. Metabolism. 2015;64(2):263-73.

23. Holzer M, Birner-Gruenberger R, Stojakovic T, El-Gamal D, Binder V, Wadsack C, Heinemann A, Marsche G. Uremia alters HDL composition and function. J Am Soc Nephrol. 2011;22(9):1631-41.

24. Holzer M, Schilcher G, Curcic S, Trieb M, Ljubojevic S, Stojakovic T, Scharnagl $H$, Kopecky CM, Rosenkranz AR, Heinemann A, et al. Dialysis modalities and HDL composition and function. Journal of the American Society of Nephrology : JASN. 2015;26(9):2267-76.

25. Weichhart T, Kopecky C, Kubicek M, Haidinger M, Doller D, Katholnig K, Suarna C, Eller P, Tolle M, Gerner C, et al. Serum amyloid a in uremic HDL promotes inflammation. J Am Soc Nephrol. 2012;23(5):934-47.

26. Tolle $M$, Huang $T$, Schuchardt $M$, Jankowski $V$, Prufer $N$, Jankowski J, Tietge UJ, Zidek W, van der Giet M. High-density lipoprotein loses its antiinflammatory capacity by accumulation of pro-inflammatory-serum amyloid a. Cardiovasc Res. 2012;94(1):154-62.

27. Kopecky C, Haidinger M, Birner-Grunberger R, Darnhofer B, Kaltenecker CC, Marsche G, Holzer M, Weichhart T, Antlanger M, Kovarik JJ, et al. Restoration of renal function does not correct impairment of uremic HDL properties. Journal of the American Society of Nephrology : JASN. 2015;26(3):565-75.
28. Koeth RA, Kalantar-Zadeh K, Wang Z, Fu X, Tang WH, Hazen SL. Protein carbamylation predicts mortality in ESRD. J Am Soc Nephrol. 2013;24(5): 853-61.

29. Shroff R, Speer T, Colin S, Charakida M, Zewinger S, Staels B, ChinettiGbaguidi G, Hettrich I, Rohrer L, O'Neill F, et al. HDL in children with CKD promotes endothelial dysfunction and an abnormal vascular phenotype. J Am Soc Nephrol. 2014;25(11):2658-68.

30. Annema W, Dikkers A, de Boer JF, Dullaart RP, Sanders JS, Bakker SJ, Tietge UJ. HDL cholesterol efflux predicts graft failure in renal transplant recipients. Journal of the American Society of Nephrology : JASN. 2016;27(2):595-603.

31. Baragetti A, Norata GD, Sarcina C, Rastelli F, Grigore L, Garlaschelli K, Uboldi P, Baragetti I, Pozzi C, Catapano AL. High density lipoprotein cholesterol levels are an independent predictor of the progression of chronic kidney disease. J Intern Med. 2013;274(3):252-62.

32. de Boer $\mathrm{H}$, Astor BC, Kramer H, Palmas W, Seliger SL, Shlipak MG, Siscovick DS, Tsai MY, Kestenbaum B. Lipoprotein abnormalities associated with mild impairment of kidney function in the multi-ethnic study of atherosclerosis. Clin J Am Soc Nephrol. 2008;3(1):125-32.

33. Speer T, Rohrer L, Blyszczuk P, Shroff R, Kuschnerus K, Krankel N, Kania G Zewinger S, Akhmedov A, Shi Y, et al. Abnormal high-density lipoprotein induces endothelial dysfunction via activation of toll-like receptor-2. Immunity. 2013;38(4):754-68.

34. Kennedy DJ, Tang WH, Fan Y, Wu Y, Mann S, Pepoy M, Hazen SL. Diminished antioxidant activity of high-density lipoprotein-associated proteins in chronic kidney disease. J Am Heart Assoc. 2013;2(2):e000104

35. Zhu X, Lee JY, Timmins JM, Brown JM, Boudyguina E, Mulya A, Gebre AK Willingham MC, Hiltbold EM, Mishra N, et al. Increased cellular free cholesterol in macrophage-specific Abca1 knock-out mice enhances pro-inflammatory response of macrophages. J Biol Chem. 2008;283(34):22930-41.

36. Kappus MS, Murphy AJ, Abramowicz S, Ntonga V, Welch CL, Tall AR, Westerterp M. Activation of liver $X$ receptor decreases atherosclerosis in $\mathrm{Ldr}(-) /(-)$ mice in the absence of ATP-binding cassette transporters A1 and G1 in myeloid cells. Arterioscler Thromb Vasc Biol. 2014;34(2):279-84.

37. Terasaka N, Hiroshima A, Koieyama T, Ubukata N, Morikawa Y, Nakai D, Inaba T. T-0901317, a synthetic liver $X$ receptor ligand, inhibits development of atherosclerosis in LDL receptor-deficient mice. FEBS Lett. 2003:536(1-3):6-11.

38. Skali H, Uno H, Levey AS, Inker LA, Pfeffer MA, Solomon SD. Prognostic assessment of estimated glomerular filtration rate by the new chronic kidney disease epidemiology collaboration equation in comparison with the modification of diet in renal disease study equation. Am Heart J. 2011;162(3):548-54.

39. Jerome WG, Cox BE, Griffin EE, Ullery JC. Lysosomal cholesterol accumulation inhibits subsequent hydrolysis of lipoprotein cholesteryl ester. Microsc Microanal. 2008:14(2):138-49.

40. Kekulawala JR, Murphy A, D'Souza W, Wai C, Chin-Dusting J, Kingwell B, Sviridov D, Mukhamedova N. Impact of freezing on high-density lipoprotein functionality. Anal Biochem. 2008;379(2):213-5.

41. Hung A, Pupim L, Yu C, Shintani A, Siew E, Ayus C, Hakim RM, Ikizler TA. Determinants of $C$-reactive protein in chronic hemodialysis patients: relevance of dialysis catheter utilization. Hemodial Int. 2008;12(2):236-43.

42. Klansek JJ, Yancey P, St Clair RW, Fischer RT, Johnson WJ, Glick JM. Cholesterol quantitation by GLC: artifactual formation of short-chain steryl esters. J Lipid Res. 1995;36(10):2261-6.

43. Yancey $P G$, Jerome WG. Lysosomal cholesterol derived from mildly oxidized low density lipoprotein is resistant to efflux. J Lipid Res. 2001;42(3):317-27.

44. Zuo Y, Yancey P, Castro I, Khan WN, Motojima M, Ichikawa I, Fogo AB, Linton MF, Fazio S, Kon V. Renal dysfunction potentiates foam cell formation by repressing ABCA1. Arterioscler Thromb Vasc Biol. 2009;29(9):1277-82.

45. Popolo A, Autore G, Pinto A, Marzocco S. Oxidative stress in patients with cardiovascular disease and chronic renal failure. Free Radic Res. 2013;47(5): 346-56.

46. Meier SM, Wultsch A, Hollaus M, Ammann M, Pemberger E, Liebscher F, Lambers B, Fruhwurth S, Stojakovic T, Scharnagl H, et al. Effect of chronic kidney disease on macrophage cholesterol efflux. Life Sci. 2015;136:1-6.

47. Kopecky C, Ebtehaj S, Genser B, Drechsler C, Krane V, Antlanger M, Kovarik JJ, Kaltenecker CC, Parvizi M, Wanner C, et al. HDL cholesterol efflux does not predict cardiovascular risk in Hemodialysis patients. J Am Soc Nephrol . 2015; 26(3):565-75.

48. Palmer SC, Navaneethan SD, Craig JC, Johnson DW, Perkovic V, Hegbrant J Strippoli GF. HMG CoA reductase inhibitors (statins) for people with chronic kidney disease not requiring dialysis. The Cochrane database of systematic reviews. 2014;5:CD007784. 
49. Holzer M, Trieb M, Konya V, Wadsack C, Heinemann A, Marsche G. Aging affects high-density lipoprotein composition and function. Biochim Biophys Acta. 2013;1831(9):1442-8.

50. Levin N, Bischoff ED, Daige CL, Thomas D, Vu CT, Heyman RA, Tangirala RK Schulman IG. Macrophage liver $X$ receptor is required for antiatherogenic activity of LXR agonists. Arterioscler Thromb Vasc Biol. 2005;25(1):135-42.

51. Ghisletti S, Huang W, Ogawa S, Pascual G, Lin ME, Willson TM, Rosenfeld MG, Glass CK. Parallel SUMOylation-dependent pathways mediate gene- and signalspecific transrepression by LXRs and PPARgamma. Mol Cell. 2007;25(1):57-70.

52. Decleves AE, Sharma K. Novel targets of antifibrotic and anti-inflammatory treatment in CKD. Nat Rev Nephrol. 2014;10(5):257-67.

53. Mkaddem SB, Bens M, Vandewalle A. Differential activation of toll-like receptormediated apoptosis induced by hypoxia. Oncotarget. 2010;1 (8):741-50

54. Fontaine C, Rigamonti E, Nohara A, Gervois P, Teissier E, Fruchart JC, Staels B, Chinetti-Gbaguidi G. Liver X receptor activation potentiates the lipopolysaccharide response in human macrophages. Circ Res. 2007;101(1):40-9.

55. Asquith DL, Ballantine LE, Nijjar JS, Makdasy MK, Patel S, Wright PB, Reilly JH Kerr S, Kurowska-Stolarska M, Gracie JA, et al. The liver $X$ receptor pathway is highly upregulated in rheumatoid arthritis synovial macrophages and potentiates TLR-driven cytokine release. Ann Rheum Dis. 2013;72(12):2024-31.

\section{Submit your next manuscript to BioMed Central} and we will help you at every step:

- We accept pre-submission inquiries

- Our selector tool helps you to find the most relevant journal

- We provide round the clock customer support

- Convenient online submission

- Thorough peer review

- Inclusion in PubMed and all major indexing services

- Maximum visibility for your research

Submit your manuscript at www.biomedcentral.com/submit 